\title{
Libertad, responsabilidad y razones morales *
}

\author{
CARLOS J. MOYA
}

Universidad de Valencia

Si la elección está causada por factores ajenos a la voluntad del agente, la libertad y la responsabilidad moral parecen perder su base. Pero si la elección carece de causas, se convierte en un acto irracional y, con ello, irresponsable. La salida de este dilema consiste en advertir la importancia de las razones morales en la deliberación práctica. De acuerdo con la tesis central del presente trabajo, la sensibilidad hacia las razones morales es una condición necesaria de la libertad y la responsabilidad moral. La inconmensurabilidad de tales razones con las razones no morales concede a la clección el lugar central que demanda la responsabilidad moral, pero, al mismo tiempo, la mantiene vinculada a la racionalidad, evitando su conversión en un acto irresponsable. Si esto es así, la disminución (o pérdida) de la sensibilidad de un agente hacia las razones morales significa también la disminución (o pérdida) de su libertad y responsabilidad moral.

No resulta difícil advertir en las sociedades occidentales actuales una progresiva disminución de la sensibilidad hacia las consideraciones específicamente morales como motivos de la acción. Entenderé por «consideraciones morales», en un espíritu kantiano, razones o argumentos que no toman en cuenta intereses particulares de un individuo o un grupo limitado de personas, bien sea una familia, un grupo étnico o una corporación, sino que presuponen la consideración de cualquier ser humano como un fin en sí mismo y no como un medio para la satisfacción de tales intereses particulares. Los presupuestos que hacen de una determinada consideración una consideración específicamente moral no son abstrusos ni están más allá del alcance de la comprensión de una persona normal. Encontramos estos presupuestos en fórmulas como "no hagas a otro lo que no quieras que te hicieran a ti mismo», así como en las diversas fórmulas del imperativo categórico kantiano, basadas en el criterio de la universalizabilidad, como uobra como si la máxima de tu acción debiera tornarse, por tu voluntad, ley universal de

* La investigación conducente a este trabajo ha sido financiada por la DGES del Ministerio de Educación y Cultura, en el marco del proyecto PB93-1049-C03-02. Agradezco a csta institución su generosa ayuda y estímulo. Agradezco asimismo al Consejo de Redacción de Isegoría, y en especial a Javier Muguerza y Antonio Valdecantos, su invitación a colaborar en el presente número de la revista. 
la naturaleza» '. Las consideraciones morales, así entendidas, no son motivos naturales de la acción humana, resultantes de un proceso evolutivo. Los motivos inducidos por este tipo de proceso natural, si atendemos a los estudios sociobiológicos, no sobrepasan el ámbito de los intereses de un grupo particular, aun cuando sca amplio. El altruismo biológicamente condicionado resulta siempre limitado por vínculos de parentesco genético, o, eventualmente, por creencias, aunque puedan ser falsas, acerca de la existencia de tales vínculos ${ }^{2}$. La aparición de consideraciones cspecíficamente morales como guías de la acción constituye una conquista histórica, un paso decisivo en el progreso cultural de la humanidad. La sensibilidad de los seres humanos hacia este tipo de consideraciones no descansa, pues, en impulsos naturales innatos, ni está garantizada por ellos, sino que depende, como la sensibilidad hacia algunos otros aspectos de lo real, de un adecuado proceso de educación, cuyos resultados no pueden ser asegurados. Depende, en suma, de procesos históricos contingentes. Esta sensibilidad hacia las consideraciones morales puede, pues, disminuir, deformarse e, incluso, perderse. Y, en mi opinión, síntomas de este proceso de disminución o pérdida son claramente perceptibles en el mundo actual. El proceso en cuestión no consiste en que las personas, enfrentadas a la elección entre razones morales y no morales, tiendan a actuar de acuerdo con las últimas. Esto, seguramente, ha ocurrido con harta frecuencia, y es parte del carácter natural de determinados impulsos y del carácter no natural de las consideraciones morales. Guiar la propia conducta por consideraciones morales es algo que, como ya vio Kant, no puede hacerse sin esfuerzo, sin un conflicto con motivos no morales, que forman parte de nuestra constitución como productos de la evolución biológica. Y los seres humanos somos muchas veces psicológicamente incapaces de llevar a cabo ese esfuerzo, o de mantenerlo de modo constante. El proceso ał que me refiero consiste más bien en que las consideraciones morales dejan de entrar en competencia con otros tipos de consideraciones, en la medida en que su fuerza como motivos de la acción deja de ser apreciada o percibida por un sujeto. Ejemplos de este tipo de proceso pueden detectarse en conflictos bélicos recientes o en curso, como el de los Balcanes, pero también en las crónicas de sucesos. Pensemos en el reciente caso del llamado «asesino del rol». Aunque no he seguido el caso con la debida atención, tengo la firme impresión de que el acusado sencillamente no comprendía por qué no debería haber matado a su víctima cuando esto era parte de un juego cn cl que estaba involucrado y que le producía satisfacción (como sucede en general con los juegos). Creo que el acusado de este crimen padecía precisamente el tipo de insensibilidad hacia las consideraciones morales al

M. Kant, Fundamentación de la metafisica de las costumbres, traducción de Manuel Garcia Morcnte, Espasa-Calpe, Madrid, 7.a ed., p. 73.

:Cf., por ejemplo, cl justamente célebre libro de R. Dawkins, El gen egoista, varias eđiciones. 
que me he estado refiriendo y que cabría llamar «ceguera moral». Por desgracia, no creo que se trate de un caso aislado.

Desde otro punto de vista, hace ya unas décadas, los pensadores de la denominada «Escuela de Frankfurt» llamaron la atención sobre algunos síntomas de este proceso, al advertir, en el campo de la deliberación práctica, el creciente predominio de la racionalidad instrumental, dirigida a la determinación de los medios más adecuados para fines no sometidos a disputa, sobre la racionalidad sustantiva, la discusión racional sobre los fines mismos, o, expresado en términos kantianos, el creciente predominio de los imperativos hipotéticos sobre los imperativos categóricos.

Entre las consecuencias obvias de este proceso de progresiva insensibilidad hacia las consideraciones morales como motivos de la acción se encuentra, sin duda, el aumento de la inseguridad, la tensión y la desconfianza recíproca entre los seres humanos, con sus secuclas de soledad y desdicha. Sin embargo, no entraré en detalle en ellas. En lo que resta del presente trabajo me ocuparé más bien de algunas consecuencias menos obvias, pero no menos importantes. Trataré de argüir, en particular, que la ceguera moral es incompatible con el libre albedrío y con la responsabilidad moral, en la medida en que el primero es una condición necesaria de la segunda. Así, en la medida en que la posesión de estas capacidades contribuye al valor de los seres humanos, una consecuencia del proceso indicado es una pérdida importante en dicho valor ${ }^{3}$.

Al afirmar que una persona afectada de ceguera moral no posee voluntad libre y no es moralmente responsable de sus acciones, no pretendo sostener que, si esta persona ha cometido un crimen, no haya razones para privarla de libertad. Io que quiero decir es que las razones que habría para ello no serian sustancialmente distintas de las que tendríamos para privar de libertad a cualquier agente que constituyese una amenaza para la vida o la hacienda de las personas. El valor que el libre albedrío confiere a quienes lo poseen se relaciona con el hecho de que permite considerarlos como origen último de un cambio, no como un mero eslabón de una cadena causal que se remonta indefinidamente en el pasado ${ }^{4}$. Un ser carente de libre albedrío no origina nada de modo radical ${ }^{5}$. Ésta es la razón por la que no consideramos a un perro, estrictamente hablando, culpable de haber mordido a alguien, aunque

${ }^{3}$ Una discusión más detallada de las bases filosóficas de esta tesis puede verse en mi trabajo “Libertad y responsabilidad morals, en J. E. Corbi y C. J. Moya (eds.), Ensayos sobre liberad y necesidad, Ed. Pre-Textos/Depto. de Metafísica, Valencia, 1997. La importancia del contenido moral de las razones para actuar ha sido destacada por Susan Wolf en su libro Freedom Within Reason, Oxford University Press, Oxford, Nueva York, 1990. En este trabajo pretendemos justificar esta importancia desde una perspectiva distinta de la adoptada por Wolf.

- Soy consciente de que esta afirmación me compromete con una forma de incompatibilismo, esto es, con la tesis según la cual la responsabilidad moral por una acción es incompatible con su determinación causal. Trataré de perfilar y justificar mi posición a lo largo de este trabajo.

Cf., para la noción de valor originante, R. Nozick, Philosophical Explanations, Oxford University Press, Oxford, 1981, cap. 4. 
sea correcto considerarle como causante de la mordedura. Decir de una persona que, en un momento dado, no actuó con voluntad libre y no es responsable de una determinada acción presupone que, en general, posee la capacidad de serlo. No es éste el sentido en que afirmamos que un sujeto afectado de ceguera moral no posee voluntad libre y no es moralmente responsable de sus acciones. Lo que queremos decir con ello es, más bien, que las nociones de voluntad libre y responsabilidad moral no tienen aplicación en su caso. $Y$ esto significa que no podemos concederle la cualidad de ser origen radical de sus propias acciones o de los efectos de las mismas.

\section{II}

Hay, en general, un amplio acuerdo en sostener que un agente no es moralmente responsable de una acción si ésta fue efecto de un poder ajeno al control del propio agente o si éste no podía haber actuado de otro modo ${ }^{6}$. Así, en términos positivos, podemos decir que un agente es moralmente responsable de una acción sólo si el agente en cucstión se determinó a sí mismo a llevarla a cabo y si podía haber actuado de otro modo. Denominaremos al primer requisito la "condición de autodeterminación" y al segundo la «condición de alternativas» ${ }^{\dagger}$. Autodeterminación y alternativas de conducta son ambas condiciones necesarias ( $y$, tal vez, aunque no nos comprometeremos con ello, conjuntamente suficientes) de la responsabilidad moral. La condición de autodeterminación corresponde al aspecto de imputación característico de las atribuciones de responsabilidad moral. Atribuir a alguien la responsabilidad de una acción es considerarle como origen o causa de la misma, de ahí que, si se puede mostrar que la causa de la acción fue ajena al propio agente, no le atribuyamos responsabilidad por ella. La condición de alternativas, por su parte, responde al supuesto natural según el cual una acción de la que un agente es responsable ha de ser una acción que dicho agente podría haber evitado y, por ello, una acción que llevó a cabo por su libre voluntad. Si no estaba en manos del agente evitar llevar a cabo una acción no está justificado hacerle responsable de clla: la acción, cabría decir, habría tenido lugar de todos modos.

- Sin embargo, este último aspecto ha sido objeto de una amplia polémica a partir de un importante articulo de Harry Frankfurt, «Alternate Possibilities and Moral Responsibility* [Joumal of Philosophy, 66 (1969), pp. 828-839], en el que se arguye que, para que un agente sea moraimente responsable de una acción, no es realmente necesario que pudiera haber actuado de otro modo. Una critica reciente de la posición de Frankfurt puede verse en $\mathrm{C}$. Ginet, "In Defense of the Principle of Alternate Possibilities: Why I Don't Find Frankfurt's Argument Convincing», Philosophical Perspectives, 10 (1996), pp. 403-417.

"Como señala Watson, «dos rasgos diferentes de la libertad... han de ser captados por cualquier concepción razonable - a saber, autodeterminación (o autonomia) y la disponibilidad de posibilidades alternativas-" (G. Watson, "Free Action and Free Will», Mind, 96 (1987), pp. 145-172, especialmente p. 145). 
La caracterización anterior de estas dos condiciones de la libertad y la responsabilidad moral es notoriamente vaga. Los problemas comienzan cuando se intenta ofrecer un análisis más preciso. ¿Qué significa propiamente autodeterminarse a actuar? ¿En qué consiste realmente tener la capacidad de actuar de otro modo? Comencemos con la primera pregunta. Supongamos que ofrecemos la siguiente respuesta: que un agente se autodetermina a actuar significa que su acción es el resultado de su propia voluntad, de su propia decisión de llevarla a cabo. Es la decisión, un acto de la voluntad, lo que presta a la acción la propiedad de estar determinada por el propio agente. En principio, esta respuesta parcce plausible y sería ampliamente aceptada, pero no elimina nuestras dificultades, como podemos ver fácilmente si preguntamos a qué se debe a su vez esa decisión. Parece razonable pensar que, si la acción ha de ser imputable al agente sobre la base de que es el resultado de su propia decisión, esta última no debería ser, a su vez, el efecto de factores no sometidos al control voluntario del agente. Si la decisión ha de poder justificar las atribuciones de responsabilidad, tendría que constituir una especie de acto originario, carente de causas, una causa incausada de la acción. La voluntad ha de poseer autonomía absoluta en su esfera de actuación para que pueda haber, en general, responsabilidad moral. Ésta es, en realidad, la posición incompatibilista, para la cual la libertad y la responsabilidad moral por una acción son incompatibles con la determinación causal de dicha acción por algo distinto de la voluntad, de la decisión del propio agente. Porque si la decisión fuese cl efecto de estados o sucesos ajenos al control voluntario del agente, éste no podría ser realmente el origen último de la acción y no cstaríamos autorizados a hacerle responsable de la misma. La decisión, por su parte, presupone alternativas, constituye un acto de elección. Este acto no puede estar determinado por causas ajenas a la voluntad del agente si éste ha de ser responsable de la acción que clige. Así, el incompatibilismo interpreta la condición de alternativas, la capacidad de obrar de otro modo, en un sentido categórico: en el momento, lugar y circunstancias externas e internas en que un agente decidió hacer $\mathrm{A}$, podría asimismo haber decidido hacer $\mathrm{B}^{8}$. Así, las circunstancias externas e internas en que tomó la decisión de hacer A no determinaron causalmente esta decisión. Esas mismas circunstancias eran compatibles con la decisión de hacer $B$. Su voluntad ha de ser absolutamente autónoma, desde el punto de vista causal, si tomamos en serio las atribuciones de responsabilidad moral.

Sin embargo, la pretensión incompatibilista de desvincular, desde el punto de vista causal, la decisión de cualquicr otro factor sobre el que el agente carezca de control voluntario amenaza con hacer de la decisión un acto arbitrario e irracional, sacrificando así la racionalidad de la acción en aras de la libertad

- Véase, sin embargo, para una crítica de esta tesis, D. C. Dennett, "No podria haber actuado de otro modo, iy qué?», en J. Corbí y C. J. Moya (eds.), Ensayos sobre libertad y necesidad, cit., pp. 133-143. El articulo de Dennett fue publicado originalmente en 1984. 
y la responsabilidad moral. Pero éste es un coste demasiado elevado. No queremos que nuestras acciones sean libres a costa de ser irracionales. Ciertamente hay factores causales que excluyen la libertad y la responsabilidad moral de un sujeto, por ejemplo la coacción externa o la compulsión patológica. Pero no deberíamos equiparar a ellos cualquier otro tipo de factor causal de nuestras decisiones. Concretamente, si nuestra decisión no ha de ser un acto arbitrario e irracional, ha de poder ser influida por nuestras razones. Una razón es, en casos típicos, un par constituido por un deseo y una creencia acerca de cómo satisfaccrlo. Para el compatibilismo, una decisión capaz de justificar la atribución de responsabilidad moral ha de estar causada, al menos, por las razones que el sujeto tiene en cuenta en el momento de decidir. La absoluta autonomía de la voluntad, incluso respecto de consideraciones racionales, propugnada por el incompatibilismo destruye en realidad la responsabilidad moral, en lugar de proporcionarle un fundamento. Podemos apreciar la dificultad a la que se enfrenta el incompatibilismo mediante un ejemplo. Supongamos que he reunido unos pequeños ahorros y deseo obtener una rentabilidad por ellos constituyendo un depósito bancario. En una sucursal del banco A, cercana a mi domicilio, me ofrecen un interés del seis por ciento. En una sucursal del banco B, igualmente cercana, me ofrecen, en cambio, un siete por ciento. Ambos bancos son igualmente solventes y me resulta igualmente cómodo operar con cualquicra de ellos. Enfrentado a una decisión, parece obvio que tengo mejores razones para optar por el banco $\mathrm{B}$ que por el banco $\mathrm{A}$. Decido, pues, depositar mis ahorros en el banco B. Esta decisión es racional, pero no está causalmente indeterminada. Las razones en favor del banco $B$ tienen más peso que las razones en favor del banco $\mathrm{A}$, y es esta mayor fuerza de las primeras la que me lleva a decidirme por el banco $\mathrm{B}$, la que, podemos decir, causa mi decisión en favor de este último. Para el compatibilismo, depositar mis ahorros en el banco $\mathrm{B}$ es una acción libre y de la que se me puede considerar responsable. Para esta posición, una acción libre, de la que un agente es responsable, no es una acción carente de causas, sino una acción que tiene causas apropiadas, en particular una acción causada por las razones que el agente tiene en cuenta. Como Ayer, un representante de esta posición, indica, «mi acción se considera como no libre, no cuando tiene una causa en general, sino cuando tione un tipo especial de causa ${ }^{9}$. El incompatibilista, sin embargo, insiste en que, si una acción ha de ser libre, la decisión de llevarla a cabo no puede estar causalmente determinada. Los problemas del incompatibilismo pueden verse con claridad si aplicamos a nuestro ejemplo su interpretación de la condición de alternativas. Para que la acción de depositar mis ahorros en el banco B sea libre, no ha de estar causalmente determinada, y esto supone que, en el momento y circunstancias en que decidí llevarla a cabo, tendría que ser verdad que yo podría haber hecho otra cosa, concretamente depositar

"A. J. Ayer, «Freedom and Necessity", en G. Watson (ed.), Free Will, Oxford University Press, Oxford, 1982, p. 21. 
mis ahorros en el banco $\mathrm{A}$. Hemos de reconocer que, en algún sentido, es verdad que yo podria haber depositado mis ahorros en el banco $\mathrm{A}$ : nadie me obligó ni me coaccionó, digamos a punta de pistola, a depositarlos en cl banco B, y nada me impedía tampoco depositarlos en el A. Podemos aceptar incluso, con Leibniz, que las razones «inclinan sin necesitar», que no son determinantes férreos e ineluctables de nucstras acciones. Supongamos, pues, que hubiese ejercido entonces mi capacidad de actuar de otro modo y que hubiese decidido depositar mis ahorros en el banco A. El problema es que, si hubiese decicido hacer tal cosa en el momento y en las circunstancias externas e internas en que me decidí por el banco $\mathrm{B}$, esa decisión en favor del banco $\mathrm{A}$ habria sido irracional, puesto que, por hipótesis, tenía mejores razones para tomar la decisión que de hecho tomé. El incompatibilista, pues, al insistir en la autonomía de la voluntad frente a cualquier otra cosa, incluidas las razones, parece incapaz de reconciliar libertad y racionalidad. El compatibilista, por su parte, puede aceptar la condición de alternativas; puede aceptar que la acción de depositar mis ahorros en el banco $\mathrm{B}$ fue libre sólo si yo podría haber hecho otra cosa (en el contexto de nuestro ejemplo, haberlos depositado en el banco A). Pero para él esto sólo puede quercr decir que yo podría haber tenido mejores razones en favor de esa alternativa (por ejemplo, que alguien podría haberme informado de que el banco $\mathrm{A}$ era, en realidad, más solvente y seguro que el B) y que, si hubiese tenido tales razones, habría optado por esa otra alternativa ${ }^{10}$. Así, el compatibilista defiende una interpretación condicional de la condición de alternativas, frente a la interpretación categórica del incompatibilista.

\section{III}

El compatibilismo tiene, como vemos, argumentos en su favor, pero no se encuentra tampoco libre de problemas. La concepción compatibilista de la acción libre, de la que un agente puede ser considerado responsable, cs, cabría decir, minimalista. Una acción libre es, sencillamente, una acción intencional, entendida cn el marco de las teorías causales de la acción: una acción que el agente lleva a cabo debido a las razones que tienc para hacerlo. El incompatibilismo, en cambio, concibe la acción libre en términos maximalistas: una acción libre es la que resulta de la voluntad incondicionada del agente, de un acto volitivo carente de determinantes causales. Para esta posición, las atribuciones de responsabilidad moral sólo pueden estar justificadas si la acción

1" Esta forma de interpretar la condición de alternativas se encuentra sugerida en D. Davidson, "Freedom to Act", en Essays on Actions and Events, Clarendon Press, Oxford, 1982, pp. 63-81. La inspiración original de esta forma de reconciliar determinación causal y alternativas de conducta se debe a G. E. Moore, según refiere I. L. Austin en su artículo alfs and Cans», Philosophical Papers, Clarendon Press, Oxford, 1961, pp. 153-180. 
se origina de modo radical en la decisión del agente, en un acto de su voluntad. Ya hemos visto algunos de los problemas que plantea esta concepción. El compatibilismo, por su parte, retrotrae la acción libre, desde el punto de vista de sus causas, a factores que no están sometidos al control voluntario del agente. Esto es, de hecho, lo que sucede con nuestras razones. Siendo pares de creencias y deseos, las razones son estados en que nos sucede hallamos, que no podemos modificar directamente a voluntad nuestra. No podemos conseguir tener una determinada creencia o deseo simplemente decidiendo tenerlos. Podemos tratar de modificar nuestras creencias y deseos indirectamente, modificando factores sometidos a nuestra voluntad, como nuestras decisiones y acciones, pero el resultado no está asegurado. Por ejemplo, alguien puede intentar que surja en él el deseo de escuchar música clásica asistiendo a conciertos y oyendo buenas grabaciones, pero puede que, pese a todos sus esfuerzos, continúe sin tener realmente ese deseo. La cuestión es, entonces, si una concepción de la acción libre como la defendida por el compatibilismo, basada en la idea de una relación causal de la decisión con creencias y deseos, con estados no sometidos al control voluntario del agente, puede ofrecer un fundamento suficiente para la responsabilidad moral. Pues del mismo modo que no depende de mi voluntad tener una u otras razones, no depende tampoco de ella la percepción que tengo de su fuerza respectiva como motivos de mi acción. El hecho de que tenga determinadas razones y mi percepción de su fuerza respectiva no deja, sin embargo, de tener una explicación causal, seguramente muy compleja, relacionada con el lugar de mi nacimiento, mi medio social, mí cducación, mi herencia genética, etc., pero sería absurdo pretender que tengo un control voluntario sobre tales factores. ¿̇Está cntonces realmente justificado atribuir a un agente responsabilidad moral por una acción cuyo origen causal no depende, y no puede depender, en último término, de su voluntad o su decisión? Pensemos en el ejemplo que antes hemos utilizado. Mi deseo de obtener una rentabilidad por mis ahorros no depende de mi voluntad. Surge en mí, seguramente, en virtud de un conjunto de factores e influencias sociales a las que he estado sometido. Puedo tal vez decidir no actuar para satisfacer ese deseo, pero esa decisión, si no ha de ser arbitraria, obedecerá asimismo a razones sobre las cuales y sobre cuya etiología no tengo, en último término, control voluntario alguno. Igualmente, no depende de mi voluntad percibir la posibilidad que me ofrece el banco $\mathbf{B}$ de obtener por mis ahorros un interés del siete por ciento como una razón más poderosa para optar por él que la posibilidad de obtener tan sólo un seis por ciento que me ofrece el banco $A$. En algún sentido, sin embargo, mi acción de depositar mis ahorros en el banco $\mathrm{B}$ es una acción libre. Pero, en este sentido, también es libre la conducta de un perro que, situado ante dos escudillas de comida, elige una de ellas. Su elección estará determinada por su percepción de la cantidad o cualidad de la comida contenida en cada una, del mismo modo que la mía está determinada por mi percepción de la diferencia en el interés 
que puedo obtener en cada caso. Pero, obviamente, el perro no es un agente moralmente responsable de sus acciones. De modo que si la estructura de mis acciones libres es semejante a la que posee mi acción de depositar mis ahorros en el banco $\mathrm{B}$, hay serias razones para dudar que nuestra convicción de que las personas son, en ocasiones, moralmente responsables de las acciones que llevan a cabo libremente esté realmente justificada. Contrariamente a lo que podemos tender a pensar, el ejercicio de nuestra capacidad de elección no nos convierte, sin más, en agentes moralmente responsables de nuestras acciones. El compatibilismo no parece capaz de ofrecer un fundamento suficiente de la responsabilidad moral. Otro modo de advertir esta insuficiencia consiste en ver que la condición de alternativas, en la interpretación condicional que el compatibilismo hace de ella, sería también satisfecha por el perro de nuestro ejemplo. Sería verdad decir de este animal que, si hubiera tenido otras "razones" para elegir, por cjemplo, si la escudilla que no eligió hubiese contenido más o mejor comida que aquella que eligió, habría optado por ella. Pero, una vez más, esto no hace del perro un agente moralmente responsable de sus acciones ". En realidad, el análisis condicional no parece satisfacer los presupuestos de la atribución de responsabilidad moral. Cuando consideramos a un agente moralmente responsable de una acción, no tenemos en cuenta lo que habría hecho en otras circunstancias, o con otros motivos u otro carácter. Presuponemos, más bien, la interpretación categórica de la condición de alternativas defendida por el incompatibilismo: asumimos que, sin un cambio en el carácter, motivos y circunstancias en las que decidió hacer A, estaba en su poder haber hecho $B$.

Esta insuficiencia del minimalismo compatibilista puede conducirnos otra vez hacia el incompatibilismo, pero entonces vamos a encontrar las dificultades que ya hemos apuntado, justamente señaladas por el compatibilismo.

\section{IV}

Nos encontramos, pues, ante un dilema, ninguna de cuyas ramas contiene una justificación satisfactoria de la responsabilidad moral. Podemos formular este dilema del modo siguiente. $O$ bien la acción de la que un agente es considerado moralmente responsable ticne como único origen causal la voluntad, la decisión del agente, o bien no lo tiene. En el primer caso, la decisión,

"Esta sería una forma de poner de manifiesto las dificultades de la interpretación condicional del principio de alternativas. Que el determinismo causal sea compatible con esta interpretación no supone que sea también compatible con la capacidad de obrar de otro modo. R. Chisholm mostró este en su «Human Frecdom and the Self", hoy en G. Watson (ed.), Free Will, cit. Una defensa reciente de la compatibilidad entre determinismo causal y alternativas podemos hallarla en T. Kapitan, "Modal Principles in the Metaphysics of Free Will", Philosophical Perspectives, 10 (1996), pp, 419-445. Sin embargo, esta defensa se ve debilitada porque en todo momento se presupone en este articulo un análisis condicional de la capacidad de obrar de otro modo. 
no estando determinada por las razones del agente y por su peso relativo, se convierte en un acto cicgo y arbitrario, de modo que no podemos considerar la acción que resulta de ese acto arbitrario como una acción de la que el agente es moralmente responsable. En el segundo caso, la decisión, y la acción que resulta de ella, dependen causalmente de factores sobre los que el agente mismo no tiene control voluntario, de modo que no podemos considerar tampoco la acción así causada como una acción de la que el agente es moralmente responsable. $Y$ si la disyunción es exhaustiva, no hay realmente responsabilidad moral. La primera rama del dilema representa la posición incompatibilista. Esta posición, cabría decir, sacrifica la racionalidad a la libertad, con lo que la libertad misma se convierte en arbitrariedad. La segunda rama del dilema representa la posición compatibilista. Esta posición sacrifica la libertad a la racionalidad.

¿Hay algún modo de escapar a este dilema y de ofrecer una justificación razonable de la libertad y la responsabilidad moral? En mi opinión, el dilema carece de salida si no introducimos en la estructura de la deliberación práctica la sensibilidad hacia las consideraciones morales ${ }^{12}$. Podemos representar la estructura característica de la deliberación práctica que conduce a una decisión y a una acción que, típicamente, consideraríamos como una acción de la que el agente es responsable del modo siguiente. Al deliberar sobre el curso de acción que va a tomar, un sujeto, $\mathrm{S}$, considera, al menos, dos cursos de acción posibles, A y B. El sujeto tiene en cuenta un conjunto de razones, $R$, en favor de la opción $A$, y otro conjunto de razones, $R$, en favor de la opción B. Supongamos ahora que, en la percepción de $S$, el conjunto $R$ tiene mayor peso que el conjunto $R^{3}$. (Podemos ignorar el caso en que, en la percepción de $S, R$ y $R$ ' tienen igual peso: un modo de resolver este caso, para $S$, es arrojar una moneda al aire.) Es plausible pensar que, si $\mathrm{S}$ es racional, se decidirá por la opción A. ¿Estamos justificados para imputarle la acción $\mathrm{A}$, en el sentido de atribuirle la exclusiva responsabilidad de esa acción?

La respuesta del incompatibilismo sería la siguiente. Percibir las razones $R$ como más poderosas que las razones $R$ ' no depende de la voluntad de $\mathrm{S}$, sino de otros factores que, en último término, no dependen de él. Así, pues, si su decisión en favor de $\mathrm{A}$ está causada por esa percepción de la mayor fuerza de $\mathrm{R}$, esa decisión, y la acción resultante, no le son, en último término, imputables. Aunque le atribuyamos responsabilidad por esa acción, esa atribución no está realmente justificada. Para que lo esté, la acción de $\mathrm{S}$ debe tener su origen último en su propia voluntad, no en otros factores

12 En un reciente articulo, pomposamente titulado "The Solution to the Problem of the Freedom of the Willw (Philosophical Perspectives, 10, 1996, pp. 385-342), John Dupré alude a la importancia de los principios morales para la libertad y la autonomía de los seres humanos, pero esta importancia no resulta justificada por ol desarrollo argumentativo de su trabajo, centrado más bien en cuestiones relativas al indetcrminismo. En el presente trabajo pretendo, por el contrario, ofrecer un argumento en favor de la importancia de las consideraciones morales y de la sensibilidad hacia su fucrza motivadora. 
no sometidos a ella. Aunque $\mathrm{S}$ decida llevar a cabo $\mathrm{A}$, debe estar en su poder decidir llevar a cabo B, sin un cambio en el contexto externo e interno en el que decide hacer $\mathrm{A}$.

El compatibilismo, por su parte, respondería del modo siguiente. La decisión de $S$ en favor de A está, ciertamente, causada por factores que no dependen de su voluntad, pero esos factores incluyen la percepción de la mayor fuerza de las razones $\mathbf{R}$ sobre las razones $\mathbf{R}$. Pues bien, a una decisión así causada es a lo que llamamos una decisión racional y a un agente, como $\mathrm{S}$, que decide de esa manera y actúa en consecuencia lo llamamos un agente responsable de su acción. Podemos imputar a $\mathrm{S}$ la acción $\mathrm{A}$ porque, aun cuando las razones que tiene en cuenta y su percepción de su fuerza relativa no dependen de su voluntad, forman sin embargo parte de él, son parte de su personalidad, de su constitución psicológica, de modo que él es el origen de su acción y estamos justificados para imputársela ${ }^{13}$. Aun cuando esté en poder de $S$ optar por B, sólo puede ejercer ese poder a costa de decidir de modo irracional e irresponsable.

La insuficiencia del compatibilismo se debe, en último término, a que no sc adecua a la radicalidad de las atribuciones de responsabilidad moral. Estas atribuciones afcetan al núcleo personal más íntimo de un sujeto, son juicios sobre una persona en los que se la considera como causa originaria de la acción, no como causa instrumental. Por ello, una teoría que concibe como causa de la acción estados o factores que no dependen del control voluntario del agente no está a la altura de cste carácter radical de las atribuciones de responsabilidad moral. En este aspecto, la exigencia incompatibilista de que la voluntad del agente, su decisión, sea la causa originaria de su acción responde adecuadamente a dicha radicalidad. Una concepción correcta de la libertad y de la responsabilidad moral debe mantener esta exigencia. Sin embargo, el compatibilismo está en lo cierto al exigir que la decisión esté adecuadamente conectada con las razones del agente, que surja causalmente de dichas razones. De otro modo la voluntad se torna arbitrariedad. No es correcto exigir, como hace el incompatibilismo, que un agente pueda actuar de otro modo como condición de su resposabilidad moral cuando el sujeto tiene razones más podcrosas para actuar como lo hace. Una concepción satisfactoria de la libertad y la responsabilidad moral ha de respetar la exigencia de que la decisión se halle apropiadamente concetada con las razones del agente ¿Podemos satisfacer conjuntamente ambas exigencias? Una vez más, mi sugerencia es que sólo podemos hacerlo si en la deliberación práctica intervienen consideraciones específicamente morales. Trataré a continuación de defender esta afirmación.

1. Donald Davidson ha insistido en este aspecto del compatibilismo. Véase su "On the Very Idea of a Conecptual Scheme», en Inquiries into Truth and Interpretation, Clarendon Press, Oxford, 1984 , p. 185. 
Veamos el papel que la sensibilidad hacia estas consideraciones puede desempeñar con vistas a la satisfacción conjunta de ambas exigencias. Abandonemos la representación puramente formal de la estructura de la deliberación práctica que hemos llevado a cabo y supongamos que, de los dos conjuntos de razones, $R$ y R', que el agente toma en cuenta, uno de ellos, digamos $R$, incluye razones de carácter moral, mientras que $R$ ' incluye razones no morales, verbigracia impulsos naturales dirigidos a la satisfacción del propio interés. Las razones morales, $\mathbf{R}$, hablan en favor de la acción $\mathrm{A}$. Las razones no morales, R', en favor de la acción $B$. Ahora bien, la introducción de razones o consideraciones morales modifica sustancialmente la situación, porque resulta plausible pensar que las razones morales y las razones no morales no son, por decirlo así, homogéneas o conmensurables, a diferencia de lo que sucedía en nuestro ejemplo del mayor o menor interés ofrecido por cada uno de los bancos. Cuando las razones son conmensurables, de modo que, en la percepción de un sujeto, se ordenan en una seric de menor a mayor peso o fuerza, el dilema de la responsabilidad moral es insoluble: la voluntad del sujeto sólo puede ser autónoma frente a esas razones a costa de entregarse a la arbitrariedad y su no autonomía sitúa el origen de la acción en factores no sometidos a la voluntad del agente. $Y$ tiendo a pensar, aunque esto requeriría mayor argumentación, que las razones de carácter no moral son, en general, conmensurables. Son sólo las razones morales las que introducen en la deliberación factores no conmensurables. Las razones morales no son más o menos fuertes o poderosas que las no morales. Son, sencillamente, de un carácter distinto.

Así, en el caso que consideramos, un sujeto dotado de sensibilidad hacia las consideraciones morales tiene tanto razones para hacer A como para hacer $\mathrm{B}, \mathrm{y}$ no podemos ya decir que tiene más razones o más poderosas para lo uno que para lo otro, debido a la esencial heterogeneidad de ambas. Podemos asi satisfacer las dos exigencias que requería una concepción satisfactoria de la libertad y la responsabilidad moral y escapar al dilema que planteábamos. Por una parte, lo que el sujeto acabe haciendo dependerá de su propia decisión, como requiere el incompatibilismo, no de sus razones, porque éstas, dada su heterogeneidad, no aparecerán ante la percepción del sujeto ordenadas de menor a mayor fuerza. Por ello podemos decir que la acción se origina radicalmente en el propio agente, en su propia voluntad, como corresponde a la radicalidad misma de las atribuciones de responsabilidad moral. Por otra parte, sin embargo, la decisión que tome el sujeto en cada caso estará apropiadamente conectada con sus razones y no será irracional o arbitraria. $\mathrm{Si}$ el sujeto decide hacer $\mathrm{A}$, ticne razones perfectamente adecuadas, de carácter moral, que le han llevado a tomar esa decisión; pero si decide hacer $\mathrm{B}$, tienc asimismo razones adecuadas que le han llevado a ello, en este caso de carácter no moral. La segunda exigencia se ve asi satisfecha. 
No cabe decir ahora, como sucedía en nucstro cjemplo de los tipos de interés, que si el sujeto decidiera hacer algo distinto de lo que de hecho decide hacer, su decisión sería irracional, porque decir esto es suponcr que las razones que tiene para hacer A y las que tiene para hacer B son conmensurables y homogéneas. Podemos respetar así la condición de alternativas en su interpretación categórica: estaba en poder del sujeto, cuando decidió hacer A, haber decidido hacer $B$, sin un cambio en el contexto externo e interno en que tomó esa decisión y sin que esa otra decisión fuese irracional.

Llegamos así al final de nuestro recorrido. Si la argumentación anterior es correcta, la progresiva falta de sensibilidad hacia las consideraciones morales, el predominio progresivo de los intereses individuales, tribales o puramente instrumentales como motivos de la acción, en la medida en que caracterice réalmente nuestra época, tendrá como resultado sujetos humanos progresivamente carentes de voluntad libre y responsabilidad moral, sujetos a los que estos conceptos no serán claramente aplicables. Y si estas capacidades confieren a los seres humanos un valor intrínseco único frente a otras criaturas, su carencia conllevará un deterioro en el valor del género humano. Este proceso no es, sin embargo, inevitable, pero es ciertamente posible. En la medida en que sepamos apreciar el valor absoluto de la voluntad buena, sensible a lo moral, hemos de trabajar activamente, tanto en lo personal como en lo social y lo político, para cvitar su progresiva degradación. 